\title{
THE RELATIONSHIP BETWEEN THE VISCO-ELASTIC AND STRUCTURAL PROPERTIES OF FINE-GRAINED SNOW
}

\author{
By P. R. KRY* \\ (Eidg. Institut für Schnee- und Lawinenforschung, 7260 Davos, Switzerland)
}

\begin{abstract}
New and felt-like snow was sieved and sintered at a constant temperature in order to produce homogeneous samples of fine, rounded-grain snow with a density in the range $270-340 \mathrm{~kg} \mathrm{~m}^{-3}$. The structure of single samples was changed in stages by non-destructive uniaxial compression. This deformation, which amounted to $30 \%$, took place within 8 hours (thus limiting temperature metamorphism). At each stage the Young's modulus was measured quasi-statically and the creep behaviour under constant uniaxial compression was recorded. Stereological analysis of sections from the samples provided mean values for both grain-bond and grain properties. The Young's modulus increased with density slightly more strongly than linearly, whereas the low-stress viscosity in unconfined compression increased nearly exponentially for densities less than $380 \mathrm{~kg} \mathrm{~m}^{-3}$. The maximum densification resulted in a 15 -fold increase in the measured visco-elastic properties. However, the number of grain bonds per unit mass increased linearly by a factor in the range 1.5 to 2 while the average grain-bond size remained constant. It is concluded that only a fraction of the grain bonds in a snow sample transmit an applied stress, and that the new grain bonds formed during the deformation of a snow sample determine the visco-elastic properties of snow. The hypothesis that chains, defined as series of stress-bearing grains, are the basic units of snow structure is developed. Semi-quantitative calculations developed from the chain concept explain the observed variations in the visco-elastic properties.
\end{abstract}

RÉsumé. La relation entre les propriétés viscoélastiques et structu relles de la neige a grains fins. Des échantillons de neige fraîche et feutrée ont été tamisśs et un frittage s'est produit à température constante; ceci assez longtemps pour produire des échantillon; homogènes de neige fine à grains ronds, d'une densité de $270-340$ $\mathrm{kg} \mathrm{m}^{-3}$. La structure de quelques échantillons particuliers a été transformée graduellement par déformation compressive non-destructive à axe unique portant sur $30 \%$ pendant 8 heures (afin de limiter la métamorphose due à la température). A chaque étape, on a mesuré quasi statiquement le module d'élasticité et on a enregistré le fluage (sous contraintes compressives constantes à axe unique). D'une analyse stéréologique de différentes sections des échantillons on a obtenu une moyenne des liaisons entre les grains et les propriétés des grains. Le module d'élasticité a augmenté avec la densité, l'accroissement étant légèrement plus fort que linéaire pendant que la viscosité s'est accrue à peu près exponentiellement sous un état de basses ccntraintes compressives à axe unique, ceci pour des densités inférieures à $38 \mathrm{o} \mathrm{k} \mathrm{m}^{-3}$. Pour la neige densifiée au maximum on a observé un accroissement des propriétés viscoélastiques mesurées d'un facteur 15 pendant que le nombre par unité de masse des liaiscns entre les grains a augmenté linéairement d'un facteur de I.5-2, la grosseur moyenne des liaiscns restant constante. D'où l'on a conclu qu'une partie seulement des liaisons entre les grains transmet une contrainte appliquée et que les nouvelles liaisons provenant de la déformation de l'échantillon, sont les plus importantes pour déterminer les prcpriétés viscoélastiques de la neige. On a établi l'hypothèse que les unités de base de la structure de la neige soient des séries de grains qui supportent les contraintes et auxquelles on donne la définition de chaînes. Des calculs semi-quantitatifs dérivés du modèle des chaînes expliquent les changements observés dans les propriétés visccélastiques.

Zusammenfassung. Die Beziehung zwischen viskoelastischen und strukturellen Eigenschaften fein Körnigen Schnees. Frischer und filziger Neuschnee wurde gesiebt und bei konstanter Temperatur genügend lang gesintert um homogene Schneeproben von fein- und rundkörnigem Schnee mit einer Dichte von 270-340 $\mathrm{kg} \mathrm{m}^{-3} \mathrm{zu}$ erhalten. Die Struktur der einzelnen Proben wurde durch eine stufenweise einachsiale Druckverformung - ohne dass dabei Brüche auftraten - geändert. Die grösste totale Deformation betrug $30 \%$ und wurde innerhalb 8 Stunden erreicht um den Einfluss der temperaturabhängigen Metamorphose einzuschränken. Bei jeder Deformationsstufe wurde der Elastizitätsmodul quasistatisch gemessen und das Kreichverhalten unter einachsialem Druckspannungszustand untersucht. Stereolcgische Analysen von Schnitten durch die Proben lieferten Mittelwerte der Kornbindungen und der Kornstruktur. Während der Elastizitätsmodul mit der Dichte leicht - aber stärker als linear - zunahm, nahm die bei niederen Spannungen (unter einachsialem Druckspannungszustand) gemessene Viskosität bei Dichten unterhalb $38 \mathrm{o} \mathrm{kg} \mathrm{m}^{-3}$ beinahe exponentiell zu. Bei der maximalen Verdichtung trat eine ${ }_{1} 5$-fache Vergrösserung der gemessenen viskoelastischen Eigenschaften auf, während die Anzahl der Kornbindungen pro Masseneinheit linear um einen Faktor von I.5 $^{-2}$ zunahm und die mittlere Grösse einer Kornbindung konstant blieb. Es wurde daraus geschlossen, dass nur ein Teil der Kornbindungen die aufgebrachten Spannungen übertragen und dass die durch die Verformung neu gebildeten Bindungen wichtig sind für die Bestimmung der viskoelastischen Eigenschaften von Schnee. Es wurde die Hypothese entwickelt, dass Ketten - definiert als Aneinanderreihungen von Körnern, die Spannungen tragen - die massgebenden strukturellen Einheiten sind. Halbquantitative, auf dem Kettenkonzept beruhende Berechnungen erklären die beobachteten Änderungen der viskoelastischen Eigenschaften.

* Present address: Production Research and Technical Service Laboratory, Imperial Oil Limited, 339-50 Ave. S.E., Calgary, Alberta $\mathrm{T}_{2} \mathrm{G}_{2} \mathrm{~B}_{3}$, Canada. 


\section{INTRODUCTION}

A fundamental problem in snow physics is the extent to which the structure of snow affects its macroscopic mechanical properties. If the structural deformation under stress is understood, then physically well-founded assumptions can be made in order to derive stressstrain relationships which will predict the behaviour of entire snow masses.

The bonds between snow grains play a significant role in the structural response to stress due to local stress concentrations which arise because the cross-sectional area of the ice has been reduced. This fact was the basis of two theoretical derivations of relationships involving porosity, one by Ballard and McGraw ( $\mathrm{I}_{965}$ ) for snow strength (the stress required to cause a rupture in the snow), and one by Feldt and Ballard (1966) for viscosity (the ratio of applied stress to resulting strain-rate) under conditions of confined compression. The importance of grain bonds is also evident from the many correlations which are found between mechanical properties and grain-bond size and number density (Hobbs, r965; Keeler, 1969). Recently, St. Lawrence and Bradley (in press) have incorporated measurements of acoustic emissions (attributed to the breaking of bonds in snow which is being deformed) into a theoretical treatment to explain the stress behaviour at a constant deformation-rate.

The structure of snow is the network of its interconnected grains. The distribution of stress by this structure influences the deformation of snow. Wakahama (1960) in his observations of the deformation of thin sections noted the importance of connectivity of the grains and introduced the idea of weak lines-lines drawn across the section to intersect a minimum amount of ice. In a three-dimensional snow sample these would be weak surfaces. He also observed that different deformation mechanisms take place in the bonds and grains. However, a danger exists in extrapolating these results to snow because the two-dimensional nature of the thin section severely restricts the freedom of movement of the observed grains and, in effect, this means that the results are applicable only to snow of very high density.

The purpose of the experiments described in this paper was to establish a relationship between the visco-elastic and structural properties of fine-grained alpine snow. This was achieved by measuring these properties as a function of density within the range $25^{\circ}-45^{\circ}$ $\mathrm{kg} \mathrm{m}^{-3}$ as the structure of a single snow sample is changed in a controlled manner. Controlled structural changes are achieved by non-destructive uniaxial deformation carried out in stages over a time short enough to limit temperature metamorphism. The procedure in such an experiment is facilitated if the visco-elastic tests and the densification are performed in the same apparatus by using compression techniques. Furthermore, the experimental results are more definitive the more homogeneous the snow and the less complex the prevailing snow grain-shape. In other words, an equi-temperature metamorphosed snow which has been artificially prepared is to be preferred.

This paper presents values of Young's modulus measured by a quasi-static technique, and gives the creep behaviour for small total strains under a steady uniaxial compression. This behaviour is analysed in terms of the Burgers body rheological model using the same approach to that which Yosida and others (1956) adopted for new snow. Quantitative measurements of the mean values of some properties of the grain bonds and grains are presented. These arise from a stereological analysis of measurements on planes taken through sections from the snow samples; the measurements were taken at increasing snow densities (Kry, 1975). The relationship between the structural and mechanical measurements is deduced by the introduction and development of the concept of a chain, a series of stress-bearing grains, as the basic unit of the snow structure. With this concept, the importance of the continuity and connectivity of the ice is emphasized, and the importance of the grain bonds is retained. 


\section{Procedure and apparatus}

Snow was prepared by sieving new or felt-like snow into $20 \times 20 \times 30 \mathrm{~cm}^{3}$ boxes and then allowing it to sinter at a constant temperature $\left(-10^{\circ} \mathrm{C}\right)$ in the covered boxes for times between 20 and $60 \mathrm{~d}$. Five different snows were prepared and arbitrarily labelled using the letters A to E. Samples cut from these snows had rounded grains less than $0.5 \mathrm{~mm}$ in size; the density of these snows varied from $270-340 \mathrm{~kg} \mathrm{~m}^{-3}$. The samples were cut to a cuboid shape with a saw to a $5 . \mathrm{I} \times 5.1 \mathrm{~cm}^{2}$ cross section ( \pm the grain size), mounted in the confining case used for densification and trimmed to a length of $15.0 \mathrm{~cm}$. Samples were never taken within $2.5 \mathrm{~cm}$ of a snow surface. The ends of the confining cases were parallel and plane to within $\pm \mathrm{I} 5 \mu \mathrm{m}$. The cut snow samples were massed to within $\pm 0.5 \mathrm{~g}$ and therefore their initial mean densities were known to $\pm 2 \%$. Errors in density determination due to changes during the experiments were $\pm 0.1 \%$ as the densities were calculated from changes in the sample length which was itself measured to within $\pm 100 \mu \mathrm{m}$.

In general, the experiments involved several stages; this is illustrated by the stress history of the single snow sample in Figure $\mathrm{I}$. In each stage the visco-elastic properties of the snow subject to a uniaxial stress were measured and the sample was then densified by a confined uniaxial compression. In the first stage (Fig. I) the prepared snow sample was cut, mounted and subjected to a uniaxial compressive pre-stress whose magnitude was comparable to the expected stresses for the visco-elastic tests. This procedure ensured a good seating of the platens. Young's modulus was then measured by a quasi-static method which involved repeated rapid straining of the snow. The creep behaviour for small total strains of the snow under a dead load was recorded as a function of time. This function yielded a quasi-steady strain-rate corresponding to the applied stress. After these two visco-elastic tests, if the structure of the sample was to be analysed, the sample was removed and a section $1.2 \mathrm{~cm}$ thick was cut from the bottom end. This was immediately immersed in 1,2-benzenedicarboxylic acid diethyl ester, frozen, and stored for analysis as described by Kry (1975). The remaining sample was re-mounted and densified. Densification was at strain-rates which averaged $5 \times 10^{-5} \mathrm{~s}^{-1}$ but which never caused a macroscopic rupture. After a given density

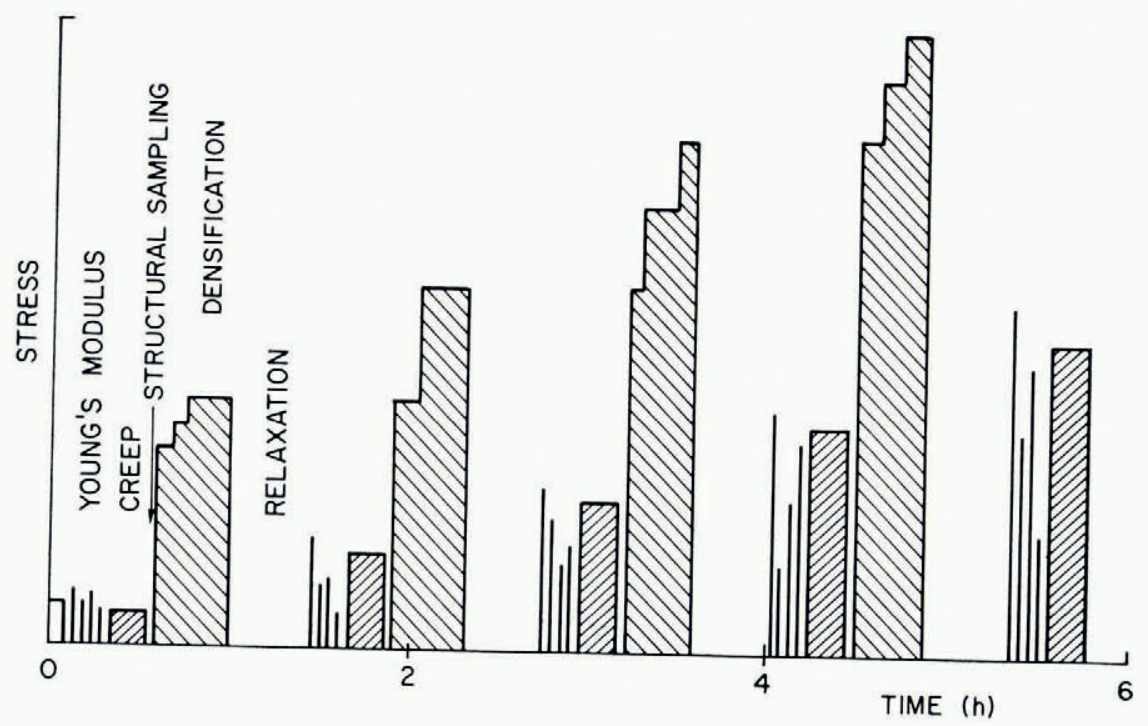

Fig. I. Schematic of the stress history of a single snow sample. 
had been achieved $\mathrm{IO}^{3} \mathrm{~s}$ were allowed for relaxation. This completed one stage of an experiment. Before the visco-elastic tests of the next stage were performed the final strain-rate was less than $10^{-7} \mathrm{~s}^{-1}$.

Figure 2 shows the mechanical press which was used to measure the visco-elastic properties and to densify the snow samples. This portable press is a modified compression-strength tester. The photograph also shows a snow sample, $12 \mathrm{~cm}$ long, mounted on a spacing block with half of the confining case which was used for densification set in place behind the sample. Rapid stresses (for measuring the Young's modulus) were applied by pulling on the spring attached to the counterbalanced lever arm. Dead loads for the creep tests were applied by placing masses in the basket. Forces on the snow sample were detected with the piezo-quartz element (KIAG Swiss Type 932 I) immediately above the top platen. The charge change of the element was amplified (KIAG Swiss 500 i charge amplifier) and then transformed to a voltage which was displayed on a storage oscilloscope (Tetronix $5 \mathrm{IO} 3 \mathrm{~N}$ ). The linearity of the sensor was $\pm 0.4 \%$ at the temperature used. All experiments were performed at $-8 \pm 0.7^{\circ} \mathrm{C}$.

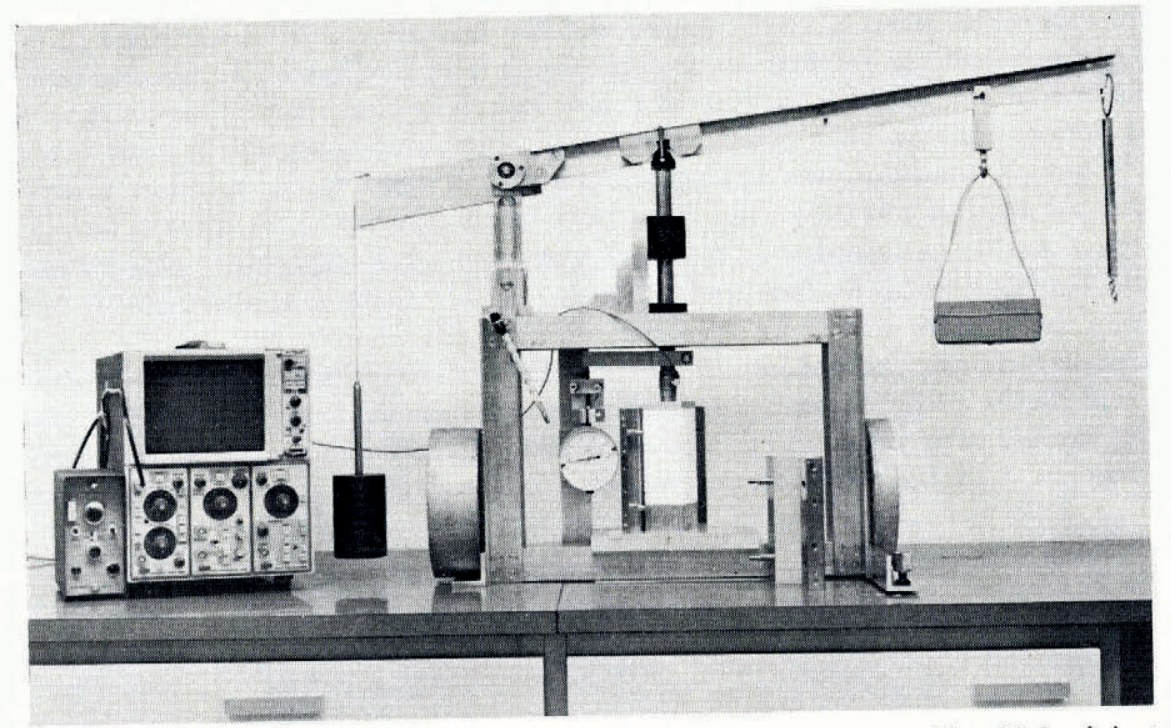

Fig. 2. Photograph of the mechanical press showing the piezo-quartz element, the dial gauge with a friction device to maintain maximum deflections and the snow probe mounted on a spacing block.

Small deformations of the sample were measured with the Tesa dial gauge which indicated deformations of $\pm \mathrm{I} \mu \mathrm{m}$, had a total error of $\pm 4 \mu \mathrm{m}$, and was linear to $\pm \mathrm{I} \mu \mathrm{m}$. For the measurement of Young's modulus the maximum deformation after a rapidly applied stress was indicated on the dial gauge. This was measured with a spring-loaded friction device (Fig. 2) which prevented the return movement of the extension arm of the dial gauge. The frictional force of this mechanism was approximately $3 \mathrm{~N}$ compared with a return force of $\mathrm{I} \mathrm{N}$ in the dial gauge.

The platens which applied the stress to the snow samples were parallel to within $\pm 15 \mu \mathrm{m}$ over their area and the spacing-block faces were parallel to $\pm 3 \mu \mathrm{m}$. All surfaces in contact with snow had a coat of teflon (polytetrafluoroethylene) which was $90 \mu \mathrm{m}$ thick. The counterweight on the lever was adjusted so as to exert a force of $1.5 \mathrm{~N}$ when there was no weight in the basket. This was to maintain contact between the platens and the snow so that initial snow lengths might be measured. Friction between the guide bearings and the load 
application shaft was less than I N. To estimate error strains due to stresses on various parts of the press, anticipated stresses were applied when a steel cylinder was between the platens. Observed deformations in this test were less than $\pm 4 \mu \mathrm{m}$. As the piezo-quartz was between the snow sample and the dial gauge, and the platen surfaces were coated with teflon, a correction was required for deformation in these parts when a force was applied. To measure the correction, a larger aluminium spacing-block was placed between the platens and loads were applied. The observed deformation $\Delta l_{\mathrm{c}}$ was found to be related to be applied force $F$ to within $\pm 2 \mu \mathrm{m}$ by

$$
\Delta l_{\mathrm{c}}[\mu \mathrm{m}]=\left\{\begin{array}{lll}
0.25 F[\mathrm{~N}] & \text { if } & F<100 \mathrm{~N} \\
25+0.14 F[\mathrm{~N}] & \text { if } & F \geqslant 100 \mathrm{~N} .
\end{array}\right.
$$

Measuring Young's modulus $E$ involved straining the snow repeatedly at a constant rate $\left(5 \times \mathrm{IO}^{-4} \mathrm{~s}^{-1}\right)$ by amounts less than $2 \times \mathrm{IO}^{-3}$ and, usually, ranging over a decade of strain. The constant rate was achieved by applying a linearly increasing force which was controlled by ensuring that the oscilloscope trace followed a pre-drawn line which was based on an estimate of $E$. For each straining the maximum strain and stress were recorded and $E$ was calculated by a least-squares analysis of this data. After each straining, the snow was relaxed for less than a minute and the dial gauge was zeroed if necessary. There was never more than $5 \%$ non-recovered strain and this was a maximum for the largest strains. After Io measurements the total non-recovered strain was usually less than $15 \%$ of the maximum strain. Before each measurement of Young's modulus snow samples had been densified or prestressed, to ensure a good contact between snow and platens.

The visco-elastic behaviour under a dead load was recorded by applying the load within two seconds and then recording the deformation as a function of time. This is illustrated in Figure 3. For the very lowest stresses, friction between the shaft and guide bearings caused a drift in the applied force which was corrected periodically by tapping the shaft lightly. Tapping the shaft when higher stresses were used did not change the creep of a given sample at a fixed density. The straight line in Figure 3 is a least-squares fit (with essentially zero error) to the data points for times greater than $360 \mathrm{~s}$.

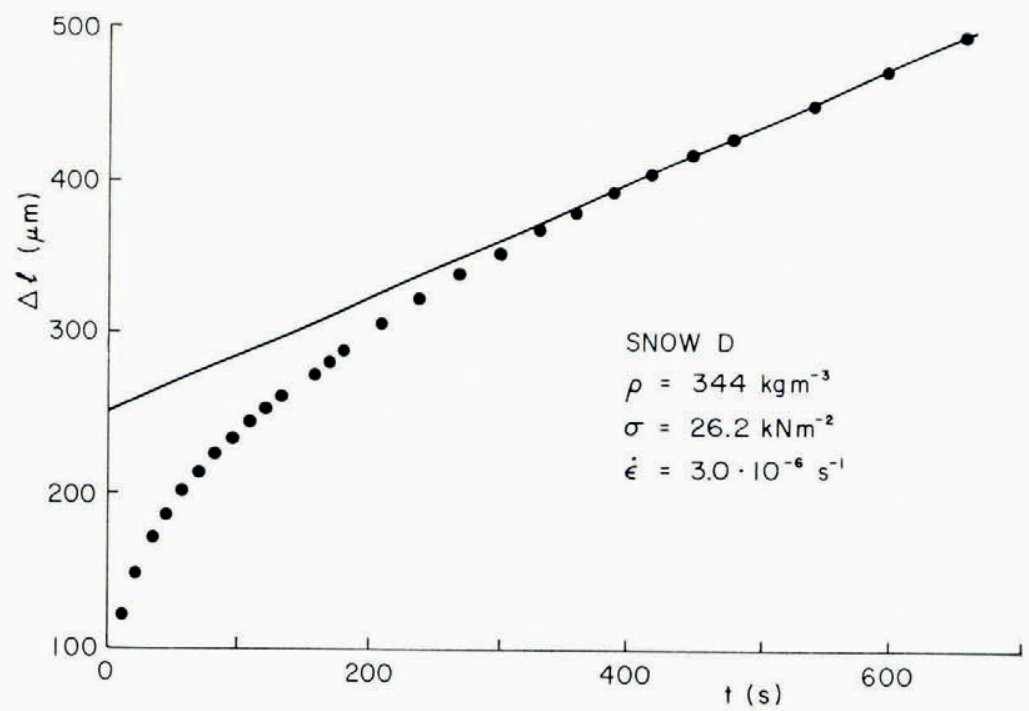

Fig. 3. Deformation $\Delta l$ under constant load $\sigma$ as a function of time $t$. Deformation rate approaching a quasi-steady strain-
rate $\dot{\epsilon}$. 
The creep data (illustrated in Fig. 3) were analysed in terms of the Burgers body rheological model (Mellor, in press) in which the strain $\epsilon$ related to a constant uniaxial stress $\sigma$ is given by

$$
\epsilon=\sigma\left\{\frac{\mathrm{I}}{E}+\frac{t}{\eta}+\frac{\mathrm{I}}{E_{\mathrm{d}}}[\mathrm{I}-\exp (-t / \tau)]\right\}
$$

where $t$ is the time, $E$ is the Young's modulus, $\eta$ is the viscosity, and $E_{\mathrm{d}}$ and $\tau$ are the Young's modulus and the time constant of the transient elastic response. The time constant $\tau$ is both the relaxation time for the body after removal of the stress and the response-time constant when a stress is applied. This identity does not necessarily hold for a complex substance such as snow and therefore the time constant measured must be identified. In these experiments $\tau$ applies to the response time of a snow sample which is suddenly subjected to stress. Thus, $\tau$ was evaluated by plotting against time the difference $\delta l$ between the actual deformation and the straight-line extrapolation of the quasi-steady creep rate. This is shown in Figure 4 for the data from Figure 3 . There is a deviation from the Burgers model as indicated by the more rapid initial response. (A similar phenomenon was observed by Gold and Traetteberg (in press) for the relaxation time in polycrystalline ice). For all experiments performed here, this shape of curve was found (Fig. 4). Furthermore, the least-squares fit to a straight line of the first $200 \mathrm{~s}$ of data gave values of $\tau$ which were independent of density for a given sample $( \pm 5 \%)$. Variations over an order of magnitude in the quasi-steady strain-rate at fixed density caused variations of $\pm 17 \%$ in $\tau$.

From the creep data of each sample (Fig. 3) a quasi-steady strain-rate associated with the applied stress was calculated from the fitted straight-line. Snow never achieves a steady strain-rate under constant load (Mellor, 1964). However, the data obtained after 360 s in these experiments is linear within experimental error, and the strain acceleration is at least two orders of magnitude less than that obtained at 6o s. Because of this and also because all the quasi-steady strain-rates were calculated from data obtained in the time range $3^{\tau-5 \tau}$ after the load was applied, all snow samples were in the same state of creep deformation.

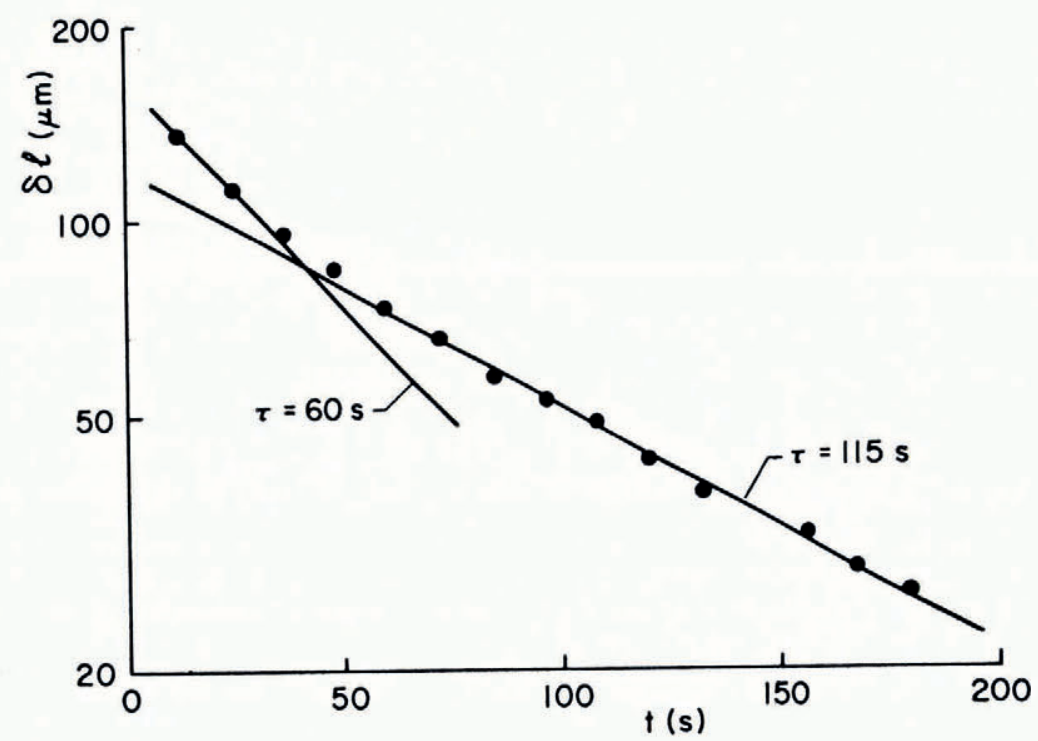

Fig. 4. Difference $\delta l$ between deformation and the linear extrapolation of the quasi-steady strain-rate as a function of time $t$. The slopes of the straight lines yield e-folding times $\tau$ for the approach of the deformation rate to quasi-steady creep. 
The relationship between quasi-steady strain-rate $\dot{\epsilon}$ and applied stress $\sigma$ can be adequately represented by a hyperbolic sine function with theoretical justification (Kennedy, I962; Mellor and Smith, 1967). The functional form is

$$
\dot{\epsilon}=\left(\sigma_{0} / \eta\right) \sinh \left(\sigma / \sigma_{0}\right)
$$

where $\eta$ is the low-stress viscosity and $\sigma_{0}$ is the normalizing plastic stress. For sufficiently low stresses the relation between $\dot{\epsilon}$ and $\sigma$ becomes linear (viscous flow), while at high stresses it is exponential (this is termed plastic deformation here). The magnitude of $\sigma_{0}$ indicates the level of stress required for plastic deformation.

In the experiments, stresses were used to characterize the creep behaviour. The loads chosen were those which gave approximately the same quasi-steady strain-rate for the different samples and densities $\left(3 \times \mathrm{IO}^{-6} \mathrm{~s}^{-1}\right)$. This strain-rate was sufficiently rapid to limit the strainmeasurement errors to less than $2 \%$ over $600 \mathrm{~s}$ while still producing a viscous flow with lowdensity snow (Table I). However, for densified snows this strain-rate occurred with plastic deformation. The error in $\eta$ is primarily due to friction in the shaft-guide bearing at the low stress levels applied; its magnitude is $\pm 10 \%$.

$\begin{array}{cc}\text { TABLE I. QUASI-STEADY STRAIN- } \\ \text { RATES } \dot{\epsilon} \text { AND THE CORRESPONDING } \\ \text { COEFFICIENT OF VISCOSITY } \eta \text { FOR } \\ \text { SNOW C AT A DENSITY OF } 307 \mathrm{~kg} \mathrm{~m}^{-3} \\ \dot{\epsilon} \\ \times 10^{5} \mathrm{~s}^{-1} & \eta \\ 0.063 & \times 10^{-10} \mathrm{~N} \mathrm{~m}^{-2} \mathrm{~s} \\ 0.107 & 0.25 \\ 0.178 & 0.26 \\ 0.296 & 0.23 \\ 0.488 & 0.24 \\ & 0.27\end{array}$

Preliminary experiments, in which samples were cut to successively shorter lengths, showed that to within $\pm 7 \%$ the visco-elastic properties were neither dependent on sample length nor affected by cutting and re-mounting. Furthermore, tests in which samples were cut from the sample box horizontally and vertically possessed initial isotropy and homogeneity to within $\pm 10 \%$.

An experiment, in which a snow sample was first densified by $10 \%$ after which its viscoelastic properties were measured as a function of time, showed variations of only $\pm 5-10 \%$ over five days. The data were reduced to one density for this test, this correction was necessary due to the large number of creep tests involved ( 17 which gave rise to a total strain of 0.04 ). Between tests there was no measurable length change in the sample. The sample was kept in a saturated environment by enclosing it in the case used to densify it initially and by surrounding the case with a plastic cover containing loose snow.

\section{RESUlts}

Figure 5 shows three typical sets of data which were used to calculate Young's modulus $E$. The representative errors in stress indicated in the Figure are due to possible calibration and reading errors. Those errors in strain include non-recoverable strain and errors in dial gauge readings. The magnitude of the initial non-linearity in the data is seen to be larger for denser snows. The unexpected stiffness at low strains partly explains the observation that the values of $E$ measured by dynamic methods are higher than those measured by quasi-static methods (Bader and Kuroiwa, 1962). Strains involved in dynamic measurements are far smaller than those occurring in quasi-static measurements and therefore represent data in our initial 


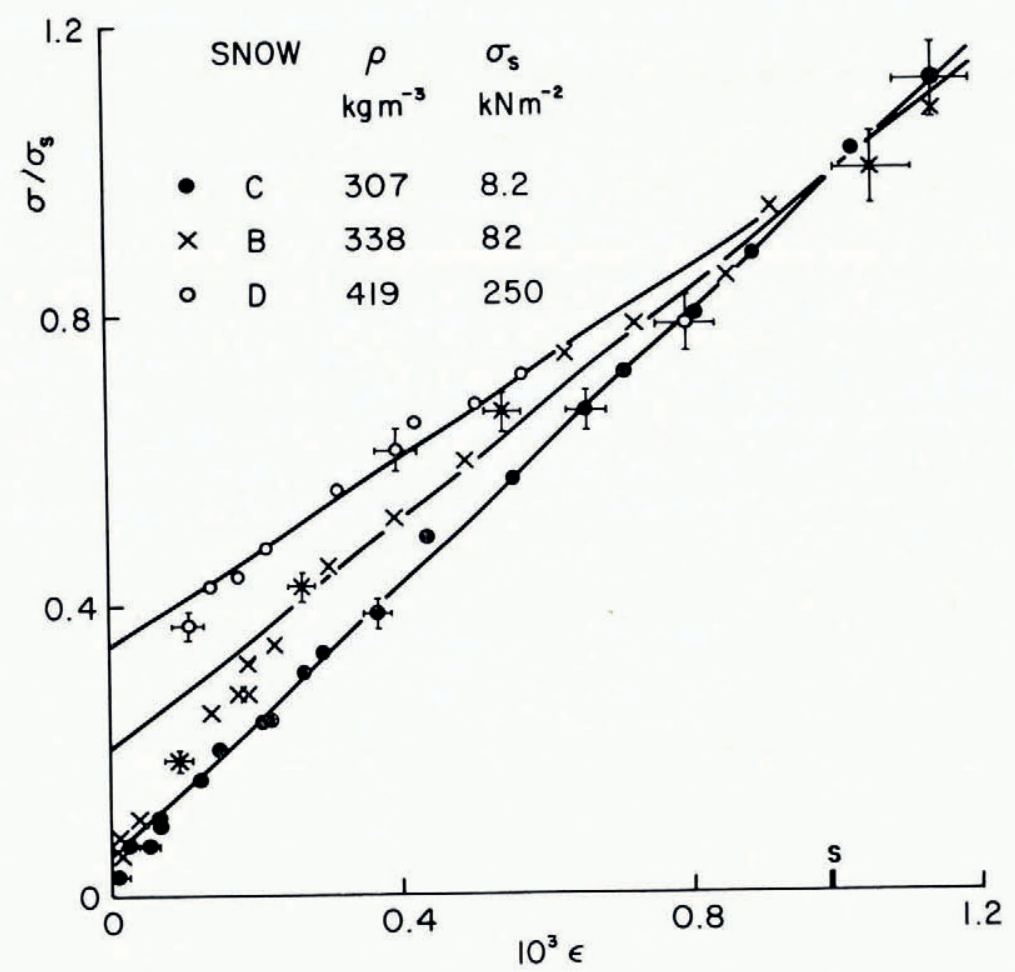

Fig. 5. Normalized stress $\sigma / \sigma_{s}$ as a function of strain $\dot{\epsilon}$ for snows uniaxially densified by different amounts. Stress normalized by that stress which causes o.ooI strain $\left(\sigma_{s}\right)$.

non-linear range. That the stiffness increases with density implies that it is a structuredependent effect. It may also be related to the stress history of the snow sample. However, the details of this were not investigated.

The data for the calculation of $E$ normally consisted of points in the linear portion of the curves only $\left(\epsilon>2 \times 1^{-4}\right)$. The slope of the best-line fit to this data (more than 9 points) had an error $\leqslant 5 \%$. A $\pm 7 \%$ error was assigned to $E$, this was based on possible errors due to temperature and strain-rate variations during an experiment. This corresponds to the reproducibility of the $E$ measurements.

The Young's modulus was found to depend weakly on strain-rate as shown in Figure 6 which is a plot of normalized Young's modulus against the strain-rate at which the measurement was made. The $E$ values were arbitrarily normalized using the value of Young's modulus at a strain-rate of $5 \times 10^{-4} \mathrm{~s}^{-1}\left(E_{s}\right)$. The data for the two snows (low and high density) show the same variation over an order of magnitude in strain-rate despite the order of magnitude difference in $E_{s}$. Hence, this variation is an ice property and is not dependent on the snow structure. Furthermore, a similar strain-rate dependence of Young's modulus in polycrystalline ice has been found by Gold and Traetteberg (in press).

The results of several creep experiments which were used to determine the stress-strainrate relationship for two snow samples are summarized in Figure 7. Snow A was one sample which was densified in stages, at each stage the quasi-steady strain-rate $\dot{\epsilon}$ for four different 


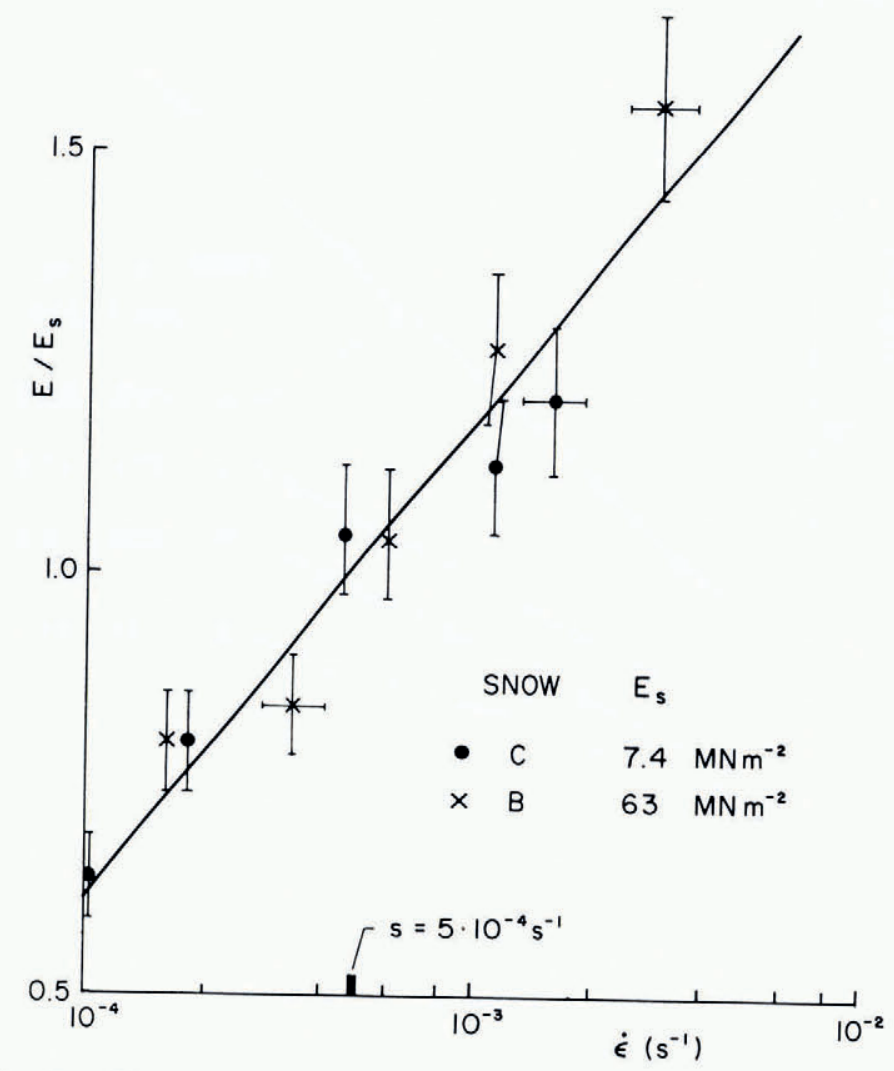

Fig. 6. Normalized Young's modulus $E / E_{s}$ as a function of the strain-rate $\dot{\epsilon}$ at which $E$ was measured, for two snows densified
by different amounts. Es measured at $5 \times 10^{-4} \mathrm{~s}^{-1}$.

stresses $\sigma$ was determined. There was only one stage of densification for snow B. The semilogarithmic plot in Figure 7 indicates that $\dot{\epsilon}$ is exponentially related to $\sigma$ as

$$
\dot{\epsilon}=K \exp \left(\sigma / \sigma_{0}\right)
$$

where $K$ is a constant and $\sigma_{0}$ is the normalizing plastic stress. In this paper deformation at strain-rates obeying Equation ( $\mathrm{I}$ ) are termed plastic.

The results in Figure 7 demonstrate that $\sigma_{0}$ is not constant as a given snow sample is nondestructively densified; the largest variation occurs in the vicinity of $400 \mathrm{~kg} \mathrm{~m}^{-3}$. Below this, $\sigma_{0}$ docs not vary strongly with density. If we assume that the onset of non-linear behaviour for a given ice sample is a constant, then the variation in $\sigma_{0}$ with density must depend directly on structural changes in the sample. Therefore, sections were taken for structural analysis at
each density for snow A.

Figures 8 and 9 show the results of the principal experiments. Following the general procedure, each of the four snow samples was subjected to cycles of testing followed by densification by incremental stages of $4 \%$ (up to a total compression of $30 \%$ ). Samples were taken for structural analysis after the first, fourth, and last sets of measurements had been made. Young's modulus (measured at a strain-rate of $5 \times 10^{-4} \mathrm{~s}^{-1}$ ) is plotted in Figure 8 as a function of density. Representative error bars are indicated $( \pm 7 \%)$. Figure 9 shows, as a 


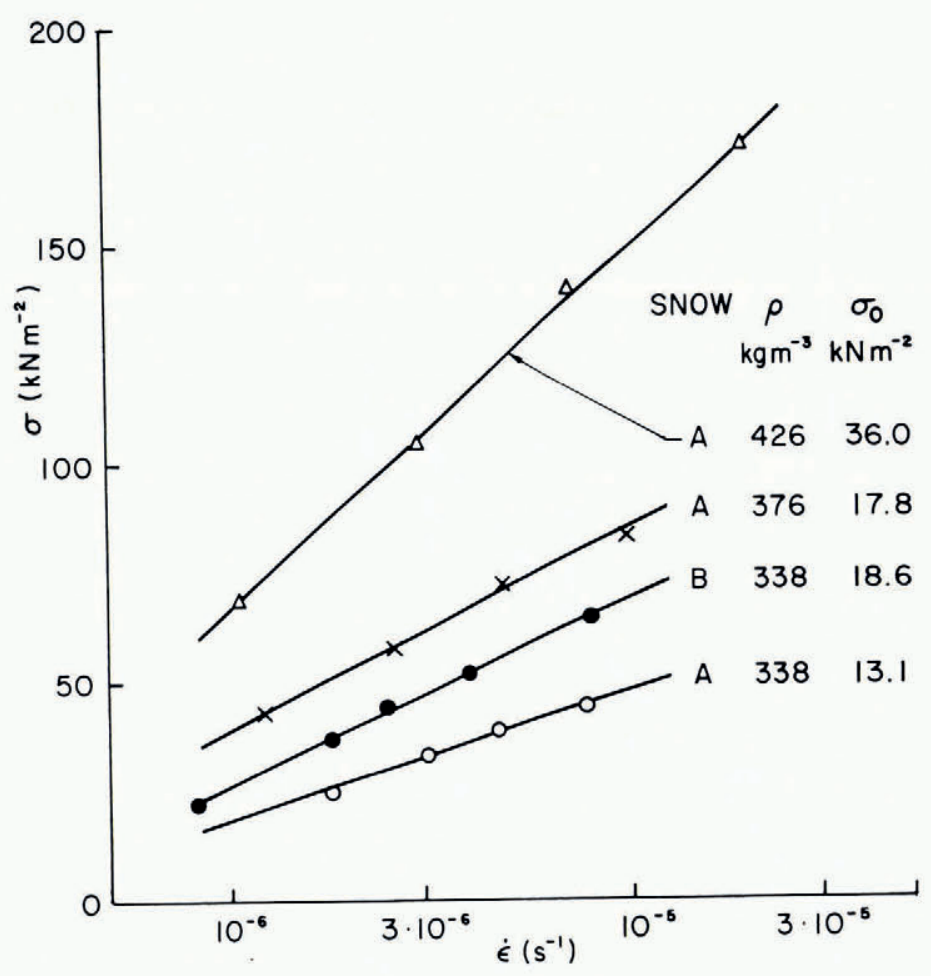

Fig. 7. Quasi-steady strain-rate $\dot{\boldsymbol{\epsilon}}$ as a function of the applied uniaxial stress $\sigma$ for two snows, one of which was successively uniaxially densified. Slopes of the lines $\sigma_{0}$ are called normalizing plastic stresses.

function of density, the stress which was applied to the samples in order to obtain a quasisteady creep-rate of $3 \times 10^{-6} \mathrm{~s}^{-1}$. The representative errors $( \pm 7-10 \%)$ shown in this Figure are based on possible errors arising from deviations in the strain-rate of $3 \times 10^{-6} \mathrm{~s}^{-1}$ (Fig. 7) or from temperature variations during the experiments. At the lowest stresses an error in the stress determination is caused by friction in the shaft-guide bearings. Since an estimate of the required load was made each time, the final quasi-steady creep-rate was not always equal to $3 \times 10^{-6} \mathrm{~s}^{-1}$. Corrections of the data for deviations from the standard strain-rate based on Figure 7 would tend to bring the points closer to the straight lines.

The results for each snow sample (Figures 8 and 9) show a I5-fold increase in the viscoelastic properties for a $30 \%$ change in density. Differences in the lowest measurements, between the four samples, illustrate the effect of densification solely as a result of equitemperature metamorphism. This densification consisted of a settling of each snow sample under its own weight after sieving. The differences of a factor 2 or less in these measurements compared with the 15 -fold increase in measurements for each snow sample establishes the significance of stress history (or corresponding deformation history) in a determination of the visco-elastic properties of a snow sample.

Creep behaviour which is important in natural snow occurs under low stresses. The combined data of Figure 7 and Figure 9 indicate that the low-stress viscosity $\eta$ in this range varies almost exponentially with density for a given snow sample which has been nondestructively densified in stages. If it is assumed that Equation (I) represents the high-stress limit of a hyperbolic sinusoidal constitutive equation, then the low-stress viscosity $\eta$ varies 


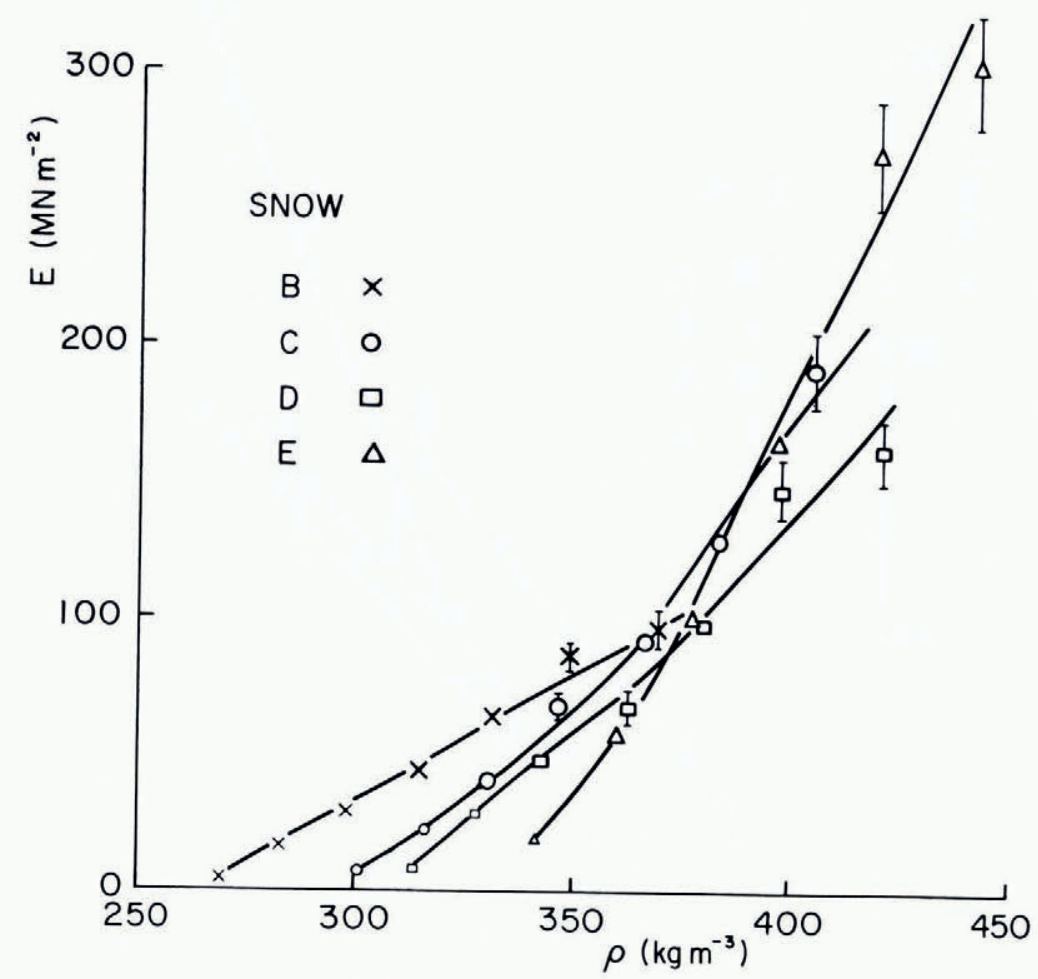

Fig. 8. Young's modulus $E$ measured at a strain-rate of $5 \times 10^{-4} s^{-1}$ as a function of the density $\rho$ for each of four snow samples uniaxially densified. Representative error bars are shown.

inversely as the factor $K$ (Equation (I)). For constant quasi-steady strain-rates this implies that

$$
\eta=\left(\sigma_{0} / \dot{\epsilon}\right) \exp \left(\sigma / \sigma_{0}\right) .
$$

The stress $\sigma$ (Fig. 9) required to produce a constant quasi-steady strain-rate increases linearly with density so that if $\sigma_{0}$ is approximately constant (densities less than $380 \mathrm{~kg} \mathrm{~m}^{-3}$ ) then Equation (2) becomes

$$
\eta=\eta_{0} \exp \left(\Delta \rho / \rho_{0}\right)
$$

where $\Delta \rho=\rho-\rho_{0}, \eta_{0}$ is a constant and $\rho_{0}$ is of the order of $30 \mathrm{~kg} \mathrm{~m}^{-3}$ using $\sigma_{0}=\mathrm{I} .5 \times \mathrm{IO}^{4}$ $\mathrm{N} \mathrm{m}^{-2}$ and an average value for the slopes of the lines in Figure 9 .

An exponential relation between $\eta$ and $\rho$ is consistent with previous results (Mellor, I964). However, for these earlier results different snow samples were used to obtain data at different densities.

The important conclusion is that $\eta$ varies much more rapidly than $E$ for an increase in density; that is, there is a difference in the structural dependence of $E$ and $\eta$. The snow structure when densified becomes much stiffer with respect to viscous deformations than with respect to elastic deformations. Furthermore, the structural dependence of the normalizing plastic stress $\sigma_{0}$ is different from those of either $E$ or $\eta$. Although $\sigma_{0}$ increases with density, the increase in $\eta$ is so much more rapid that plastic flow occurs at progressively lower strain-rates for increasing density. Any attempt to explain snow structure must account for these three separate dependences. 


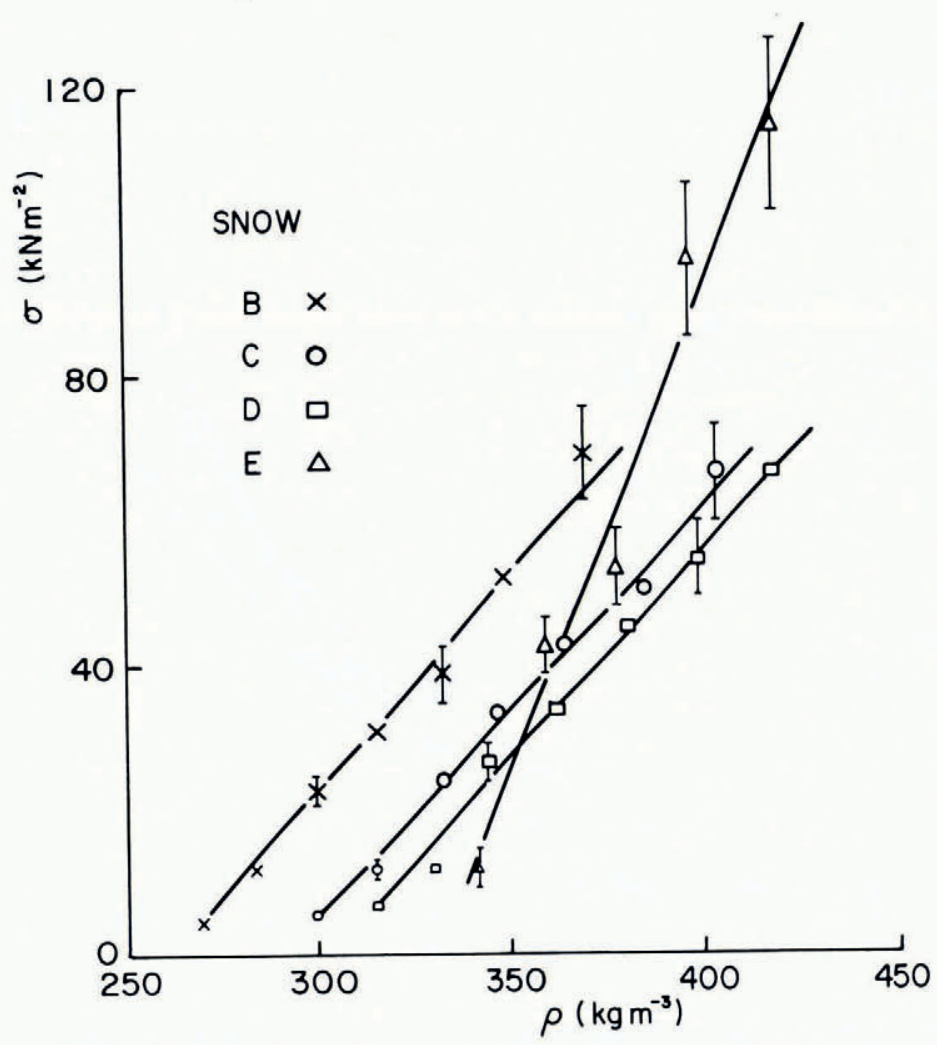

Fig. 9. Steady uniaxial stress $\sigma$ resulting in a quasi-steady strain-rate of $3 \times 10^{-6} s^{-1}$ as a function of the density $\rho$ for each of four snow samples uniaxially densified. Representative error bars are shown. The point $(445,17.4)$ for snow $E$ has been omitted.

The structural analysis resulted in quantitative measures of mean grain and grain-bond properties (Kry, 1975). A grain bond is the plane surface of minimum area in the neck region of two linked grains. It can be assumed to be a circular disk.

Results of the structural analyses of sections appear in Table II. For each snow (A to E) the section of highest density is an average of evaluations from planes perpendicular and parallel to the applied stress. As shown in Kry (1975) these gave equal results which established the isotropy and randomness of grain-bond and grain orientations, and locations. The indicated errors in Table II are primarily statistical being based on the numbers of features counted, but they also correspond to the inhomogeneity observed in the snow samples. They do not contain possible systematic errors. However, such errors would not affect relative relationships.

The mean grain properties (Table II) are the mean intercept length $L_{3}$ and the mean-freepath between grains $d$. Both are defined as the mean length in three dimensions of a straight line from grain surface to grain surface, $L_{3}$ within a grain and $d$ between grains. The mean intercept length $L_{3}$ is therefore a statistical measure of the mean grain size. Table II shows that $L_{3}$ within the statistical error is a constant, as it must be. Neither $L_{3}$ nor $d$ depend on any assumptions concerning grain-shape or size distribution.

The surprising result from Table II is that the mean grain-bond radius $\dot{r}$ (in three dimensions) remains a constant under deformation, despite the fact that the number of grain bonds 
almost doubles. This may result from the snow samples consisting of old snow with well sintered rounded-grains. The grain-bond size in such snow has reached a plateau in its growth which is not exceeded until the grain size or the nature of the structure changes drastically. Keeler ( 1969 ) found that the ratio of the mean radii of the grain bonds and grains seemed to stabilize at a value of 0.25 . From Table II, $\bar{r} / L_{3}$ is constant for all snows at 0.20 $\left(\tilde{r} / R_{e}=0.26\right.$, where $R_{e}$ is the radius of the sphere with a mean intercept length of $\left.L_{3}\right)$. Grain bonds formed under stress may tend to approach this limit directly and this would explain why $\dot{r}$ remains constant after densification.

TAble II. Structural properties of Five SNOW SAmples Which Were Densified Uniaxially

\begin{tabular}{|c|c|c|c|c|c|c|c|c|}
\hline Sample & $\begin{array}{c}\rho \\
\mathrm{kg} \mathrm{m}^{-3}\end{array}$ & $\begin{array}{c}L_{3} \\
\mathrm{~mm}\end{array}$ & $\begin{array}{c}d \\
\mathrm{~mm}\end{array}$ & $\begin{array}{c}S_{\mathrm{V}} \\
\mathrm{mm}^{-1}\end{array}$ & $C$ & $\begin{array}{c}\bar{r} \\
\mathrm{~mm}\end{array}$ & $\underset{\mathrm{mm}^{-3}}{\mathcal{N}_{\mathrm{v}}}$ & $\begin{array}{c}\bar{A} \\
\times 10^{3} \mathrm{~mm}^{2}\end{array}$ \\
\hline A & $\begin{array}{l}338 \\
376 \\
426\end{array}$ & $\begin{array}{l}0.26 \\
0.24 \\
0.26\end{array}$ & $\begin{array}{l}0.45 \\
0.35 \\
0.30\end{array}$ & $\begin{array}{l}0.11 \\
0.15 \\
0.20\end{array}$ & $\begin{array}{l}0.037 \\
0.042 \\
0.054\end{array}$ & $\begin{array}{l}0.057 \\
0.061 \\
0.057\end{array}$ & $\begin{array}{l}\text { I I } \\
\text { I } 6 \\
2 \text { I }\end{array}$ & $\begin{array}{l}9.8 \\
9 \cdot 1 \\
9 \cdot 7\end{array}$ \\
\hline B & $\begin{array}{l}270 \\
315 \\
369\end{array}$ & $\begin{array}{l}0.22 \\
0.20 \\
0.22\end{array}$ & $\begin{array}{l}0.52 \\
0.38 \\
0.33\end{array}$ & $\begin{array}{l}0.077 \\
0.14 \\
0.17\end{array}$ & $\begin{array}{l}0.028 \\
0.038 \\
0.045\end{array}$ & $\begin{array}{l}0.040 \\
0.045 \\
0.041\end{array}$ & $\begin{array}{l}14 \\
19 \\
30\end{array}$ & $\begin{array}{l}5 \cdot 5 \\
7 \cdot 4 \\
5 \cdot 7\end{array}$ \\
\hline c & $\begin{array}{l}301 \\
349 \\
406\end{array}$ & $\begin{array}{l}0.18 \\
0.20 \\
0.22\end{array}$ & $\begin{array}{l}0.37 \\
0.32 \\
0.27\end{array}$ & $\begin{array}{l}0.10 \\
0.12 \\
0.22\end{array}$ & $\begin{array}{l}0.028 \\
0.030 \\
0.051\end{array}$ & $\begin{array}{l}0.044 \\
0.038 \\
0.042\end{array}$ & $\begin{array}{l}16 \\
27 \\
38\end{array}$ & $\begin{array}{l}7 \cdot 5 \\
4 \cdot 5 \\
5 \cdot 7\end{array}$ \\
\hline D & $\begin{array}{l}314 \\
3^{6} 3 \\
4^{21}\end{array}$ & $\begin{array}{l}0.22 \\
0.23 \\
0.24\end{array}$ & $\begin{array}{l}0.43 \\
0.35 \\
0.28\end{array}$ & $\begin{array}{l}0.12 \\
0.16 \\
0.27\end{array}$ & $\begin{array}{l}0.038 \\
0.044 \\
0.065\end{array}$ & $\begin{array}{l}0.045 \\
0.048 \\
0.046\end{array}$ & $\begin{array}{l}14 \\
19 \\
35\end{array}$ & $\begin{array}{l}8.6 \\
8.4 \\
7.8\end{array}$ \\
\hline $\mathrm{E}$ & $\begin{array}{l}343 \\
378 \\
445\end{array}$ & $\begin{array}{l}0.27 \\
0.23 \\
0.30\end{array}$ & $\begin{array}{l}0.46 \\
0.33 \\
0.31\end{array}$ & $\begin{array}{l}0.12 \\
0.15 \\
0.24\end{array}$ & $\begin{array}{l}0.04 \mathrm{I} \\
0.040 \\
0.068\end{array}$ & $\begin{array}{l}0.052 \\
0.053 \\
0.055\end{array}$ & $\begin{array}{l}12 \\
17 \\
26\end{array}$ & $\begin{array}{l}9.5 \\
8.9 \\
9 \cdot 3\end{array}$ \\
\hline Relative error $\%$ & \pm 2 & \pm 7 & \pm 7 & \pm 10 & $\pm \mathrm{I} 2$ & \pm 6 & \pm ro & $\pm \mathrm{I}_{5}$ \\
\hline
\end{tabular}

Density, $\rho$; mean intercept length, $L_{3}$; mean free path from grain surface to grain surface, $d$; grain-bond surface area per unit volume, $S_{\mathrm{v}}$; contiguity, $C$; mean grain-bond radius, $\bar{r}$; number of grain bonds per unit
volume, $\mathcal{N}_{\mathrm{v}}$; mean grain-bond area, $\bar{A}$.

The principal change in the bonding properties of snow as it densifies is the creation of new grain bonds as shown by $\mathcal{N}_{\mathrm{v}}$ the number of grain bonds per unit volume in Table II. The independent measure of $S_{\mathrm{v}}$, the total surface of grain bond per unit volume, also indicates that, since the mean grain-bond area $\bar{A}$ remains constant for each sample only the number of grain bonds is changing. That $\bar{A}$ is a constant implies that the variance in the distribution of grainbond sizes is a constant. However, the error range for $\bar{A}$ weakens this latter conclusion since the variance is proportional to the difference between two nearly equal quantities, $\bar{A}$ and $\pi \bar{r}^{2}$. Dividing $\mathcal{N}_{\mathrm{v}}$ and $S_{\mathrm{v}}$ by the density yields the number of bonds and the total area of grain bond per unit mass; in samples of constant mass, changes in these parameters are due exclusively to the formation of new grain bonds. In Figures Io and I I $S_{\mathrm{v}} / \rho$ and $\mathcal{N}_{\mathrm{v}} / \rho$, have a $1.5^{-}$to $2-$ fold increase for a $30 \%$ non-destructive densification. This is far smaller than the change in the visco-elastic properties for the same densification. The linear variation of $\mathcal{N}_{\mathrm{v}} / \rho$ with density implies that for equal strain changes more new grain bonds are formed at higher densities. This result is not unexpected since the mean distance between grains decreases as $\rho$ increases. As $\mathcal{N}_{\mathrm{v}} / \rho$ varies linearly with density and the mean area of grain bond remains constant $S_{\mathrm{v}} / \rho$ must also vary linearly with density. The ratio of slopes for each snow from Figures io and I is the constant mean size of the new grain bonds for that snow. A quantitative comparison of the ratios shows agreement with the results in Table II. 


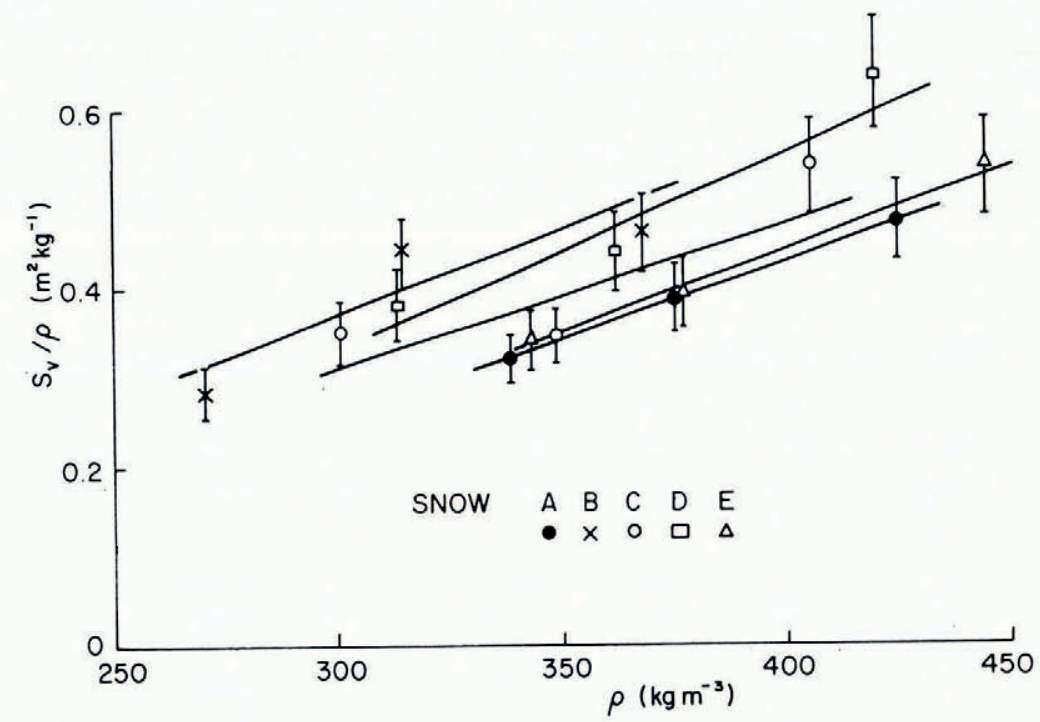

Fig. Io. Total grain-bond surface area per unit mass $S_{\mathrm{v}} / \rho$ as a function of density $\rho$ for each of five snow samples uniaxially densified.

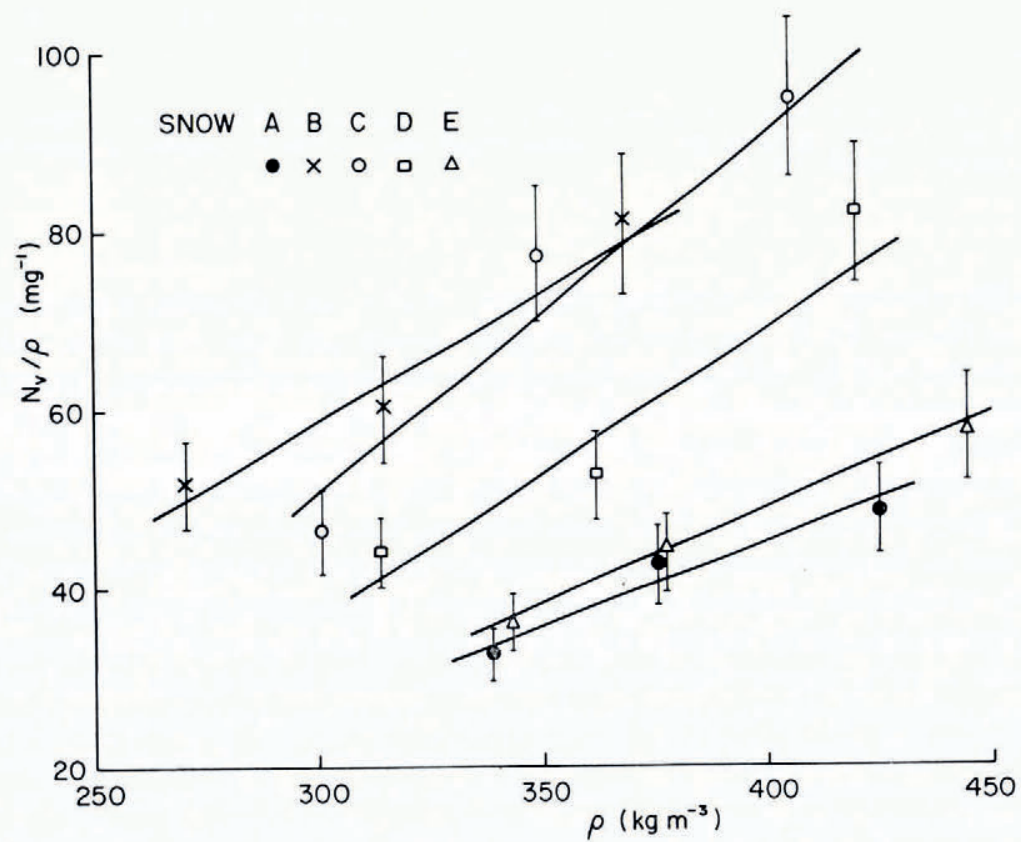

Fig. II. Number of grain bonds per unit mass $\mathcal{N}_{\mathrm{v}} / \rho$ as a function of density $\rho$ for each of five snow samples uniaxially densified. 


\section{Discussion}

The establishment of the relationship between the structural and mechanical properties of snow requires the identification of the fundamental unit of snow structure. The defining property of such a unit is that, for a given stress on a snow sample, the strain of the average elementary unit must equal that of the snow sample.

Individual grain bonds cannot serve as fundamental units since a 1.5 - to 2 -fold increase in the number of grain bonds (Fig. I I) cannot directly explain a 5 -fold increase in mechanical properties (Fig. 8 and Fig. 9). However, due to associated stress concentrations, the neck regions of grains near grain bonds (within a distance $\dot{r}$ from the bond) must play an important role in the total deformation. For the same given states of stress in a grain and in the neck

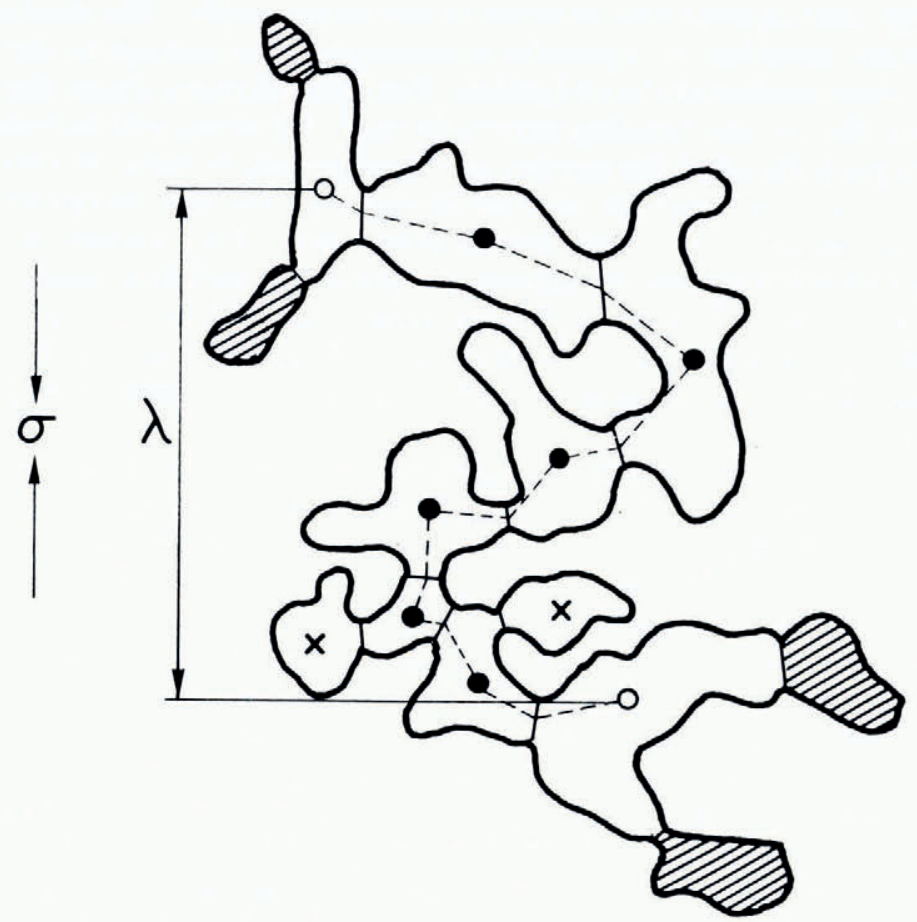

Fig. I2. Sketch of a chain of length $\lambda$ in the direction of applied stress $\sigma$. Points indicate grain geometric-centers: $\bigcirc$, end grains;, link grains; $\times$, branch grains.

region, the stresses in the central part of the grain are $\left(\tilde{r} / L_{3}\right)^{2}$ times smaller than those in the neck region (stress concentration by area). However, strain in the grain extends approximately over a distance $L_{3}$, compared to a distance $\tilde{r}$ for the strain in the neck region. Therefore, for the combination of a grain and grain bond, the total strain in the grain is a factor of the order of $\tilde{r} / L_{3}$ smaller than that in the neck region. For the snows in these experiments this factor is 0.2 and therefore the principal deformations occur near grain bonds.

It is proposed that the fundamental units of snow structure are chains-series of connected grains transmitting a single force (Fig. 12). With this definition, the importance of individual bonds is combined with the connectivity of the snow grains. The extent to which the concept explains snow behaviour provides the justification for its application and further use. 


\section{Chain concept}

Whether a series of grains acts as a chain or not depends on the stress on the snow sample. For simplicity, and in accordance with the experimental procedure adopted, it is assumed in this discussion that the macroscopic states of stress are uniaxial.

Figure 12 shows the geometry of a chain schematically. For each snow sample individual grains are classified either as link grains, which transmit the force along the chain and have two stressed bonds; or as branch grains, which transmit no significant stress although connected to a chain; or as end grains, which have three or more stressed bonds. The length of the chain is defined as the sum of the lengths of the straight-line segments which join grain centers to grain-bond centers and is further defined to start and end at the center of an end grain. If, on the average, there are $\mathcal{N}_{\mathrm{c}}$ stressed grain bonds per chain then the mean chain length is $\mathcal{N}_{\mathrm{c}} L_{3}$. The projection $\lambda$ of this length along the macroscopic stress direction is then the base length for relating strain in the chain to strain in the snow sample. The greatest extent of the chain normal to the direction of $\sigma$ provides a measure of the average of the torques in the chain due to the forces applied at the end grains. For more eccentric chains the torques will be greater and hence the average bending stresses through the chain will increase.

As a snow sample is densified the number of chains per unit volume $M$ increases as a result of the creation of new chains and the decrease in volume. The new chains are formed when two grains are pushed into contact and form a grain bond. For example, if two link grains come into contact they will become end grains for new chains and four chains will exist where previously there were two. The types of the two grains (end, link or branch) which come into contact determine whether one, two, or three new chains are formed. If each of the six cases has an equal probability of occurrence, then two chains are formed on average by each new grain bond.

The formation of new bonds must occur primarily during the relaxation process after the densification stress is removed. This is evident from a comparison of the results in Figure 9 and some results from compression experiments over large strain intervals at a constant strain-rate with no intermediate relaxation (Salm, I97I). In the latter case the stress is essentially constant $( \pm 10 \%)$ once quasi-steady creep occurs for strains of up to 0.05 . However, a similar deformation with an intermediate relaxation results in a doubling of the stress required for the same quasi-steady strain-rate (Fig. 9).

The strain-rate during the relaxation process steadily decreases as the snow block extends. Below a certain rate the relative motion between most of the sliding grains is sufficiently slow for the contacts to adhere, halt the motion and form grain bonds. The tendency to surface adhesion is the same effect as that responsible for the agglomeration of snow crystals to form snow-flakes (Hosler and others, 1957). The new bonds formed can be divided into two classes: strong grain bonds, in which the contact was achieved before the densification stress was removed; and weak grain bonds, in which the contact was achieved after the stress was removed. On the average, because the strain involved during relaxation is relatively small, the weak grain-bonds would have much smaller surface areas than the strong grain bonds and would be the grain bonds to be broken first when a compressive stress is re-applied.

\section{Deformation mechanisms}

The deformation of a chain is assumed to be due to deformations in the neck regions of grains near grain bonds. For elastic deformations this may be visualized as a bending strain caused by torques due to the eccentricity of the chain. The exact mechanism for viscous flow is unknown. However, it can be inferred from the existence of a viscous deformation of the whole snow sample (stress linearly related to strain-rate) that there is a viscous deformation in the individual grain bonds. That is, what is linear on the scale of the snow sample is linear on the scale of the snow grain. 
There are at least two possible viscous flow mechanisms. One is that bending (Krausz, 1972) occurs in analogy to the elastic deformation. The other is that the glide at crystal bonds, the surface between two crystals, obeys a viscous flow law at low stresses (the dislocations at the crystal bond behaving as a viscous oil-layer). Since crystal bonds and grain bonds are, in general, coincident (and must be for all bonds formed during deformations of a snow structure), the glide mechanism must be active in the same regions as the bending mechanism. However, the glide is a shear deformation rather than a bending deformation. In both cases migration of dislocations at the grain bond probably plays a major role in the deformation mechanism.

For plastic flow it is assumed that other deformation mechanisms, principally basal glide in the snow grains (Wakahama, 1960), become activated at higher stress levels.

\section{Qualitative description of snow compression}

Consider a snow sample subjected to the general procedure of these experiments. During the relaxation periods new grain bonds are formed (strong and weak). When a stress is applied subsequently the weak grain bonds break. As long as the stress applied is less than the pre-stress during densification no strong grain bonds break, since the pre-stress established an optimum structure.

For the elastic tests, once the weak grain bonds are broken, the deformation is a pure elastic deformation of the chains. However, during the initial deformation the work done in breaking the weak grain bonds causes the snow to appear stiffer. This is the explanation of the initial non-linearity in Figure 5 in terms of the chain concept. The time between stress applications in the elastic tests $(30-60 \mathrm{~s})$ is sufficient for the weak grain bonds to re-form and hence give reproducible results.

For the viscous tests, the weak grain bonds are broken by the initial application of the dead load and the ice in the vicinity of the grain bonds begins to deform in the way shown by the strain-time curve in Figure 3. No new bonds form during the test as the grains brought into contact have a sufficiently rapid motion relative to each other.

If the stress is increased much above the pre-stress further grain bonds will break as the structure re-adjusts to distribute the new maximum stress in an optimum way. It is thought that this is the mechanism of the Kaiser effect in snow which has been observed by Bradley and St. Lawrence (in press).

\section{Normalizing plastic stress}

The data shown in Figure 7 were used to estimate the variation of $M \lambda$, the number of chains intersected by a plane of unit area perpendicular to the applied stress as a function of density. The principal assumption was that the normalizing plastic stress for the average chain does not depend on the chain length. This is justified in part if the plastic deformation is due to shear deformations, since the grain and grain-bond size do not change as the snow is densified. Shear stresses in the chains do not depend on the torques generated by the eccentricity of the chain and, hence, are independent of chain length. This assumption implies that increases in $\sigma_{0}$ (Fig. 7) for increasing densities of snow A are due to increasing numbers of chains bearing the stress. That is, if at each density the corresponding normalizing plastic stress is applied to the sample, the average force on a chain will be constant. Thus, $\sigma_{0} / M \lambda$ is a constant for a given snow. For snow a the ratios of the number of chains bearing the stress at lower densities to the number at $426 \mathrm{~kg} \mathrm{~m}^{-3}$ were found to be

$$
(M \lambda)_{426}:(M \lambda)_{376}:(M \lambda)_{338}=\text { I.o }: 0.49: 0.36 .
$$




\section{Young's modulus}

The variation of Young's modulus with density can be explained in terms of an elastic stiffening of the chains as they become shorter and less eccentric. For a given force applied on the end grain of a chain, as the chains become less eccentric the average bending stresses near the grain bonds become smaller. That is, the average deformations are less in shorter chains if equal forces are applied to the chains.

If $\epsilon_{\mathrm{b}}$ represents the strain in the vicinity of a grain bond, which is a perpendicular distance $L_{3}$ from the center of an end grain, then $k \epsilon_{\mathrm{b}}$ represents the deformation in the vicinity of a grain bond which is a perpendicular distance $k L_{3}$ from the center of an end grain. (On the average, the applied forces on the end grains can be treated as being applied at the center of the end grains). For the two extreme cases of one grain bond in the average chain and ten grain bonds in the average chain, $k$ varies from $(2 \sqrt{2})^{-1}$ (for a bond oriented at $45^{\circ}$ to the force on the end grain) to something less than 5 (for the mean distance of the grain bonds from the end grain to be a maximum). Thus, when the number of bonds per chain varies from io to I a factor decrease of from 5 to io in $k$ would be expected.

The strain in the chain is the average strain $k \epsilon_{\mathrm{b}}$ multiplied by the factor $\tilde{r} / L_{3}$ (the relative range of strain in the vicinity of the bond). Therefore, equating the chain strain to the snowsample strain allows the expression for the Young's modulus of snow to be written as

$$
E=\left(\frac{L_{3}}{\bar{r}}\right) \frac{\sigma}{k \epsilon_{\mathrm{b}}}
$$

where $\sigma$ is the applied stress. As $M \lambda$ chains per unit area carry this stress, the average force on a chain is $\sigma / M \lambda$. This is proportional to the strain $\epsilon_{\mathrm{b}}$. If a force $\sigma / M \lambda$ is applied a perpendicular distance $L_{3}$ from a single grain bond (radius $\tilde{r}$ ) the bending stress would be $a(\sigma / M \lambda) L_{3} / \tilde{r}^{3}$ where $a$ is a factor depending on the form of the neck region. If $E_{\mathrm{b}}$ is an appropriately defined elastic modulus for bending the ice then

$$
a\left(\frac{\sigma}{M \lambda}\right) \frac{L_{3}}{\dot{r}^{3}}=E_{\mathrm{b}} \epsilon_{\mathrm{b}} .
$$

Combining Equations (5) and (6) yields an expression for the Young's modulus of snow as

$$
E=\left(\frac{M \lambda}{k}\right)\left(\frac{\dot{r}}{L_{3}}\right)^{2} L_{3}^{2}\left(\frac{E_{\mathrm{b}}}{a}\right) .
$$

Combined variations of a factor 3 in $M \lambda$ (Equation (4)) and 5 in $k$ account for the observed 15 -fold increase in Young's modulus of snow which has been densified by $30 \%$. Furthermore, as predicted from Equation (7) the faster increase in $E$ at higher densities, shown in Figure 8, corresponds to the sharp increase in $M \lambda$ at the highest density in Equation (4).

The increase of Young's modulus with density can be expressed in terms of changes in $\mathcal{N}_{\mathbf{v}} / \rho$, the number of bonds per unit mass in the sample. According to Equation (5) two factors can change Young's modulus as the density increases: $M / \rho$, the number of chains per unit mass of the sample; and $\rho \lambda / k$, a factor which depends only on the chain length. As the snow is densified $\lambda$ decreases due to the formation of new shorter chains and the deformation of old chains. Because the densification is uniaxial and $\lambda$ is the mean chain length in the direction of the strain, decreases in $\rho \lambda$ are due only to the formation of new shorter chains. However, decreases in $k$ also depend on the formation of new shorter chains so that $\rho \lambda / k$ will tend to have a small variation with density. Therefore, variations in $E$ result primarily from variations in the number of chains per unit mass. On the average, two new chains, are formed by each new bond so that after a densification $2 \Delta\left(\mathcal{N}_{\mathrm{v}} / \rho\right)$ new chains are formed. These considerations imply that 


$$
\Delta E \propto\left(\frac{\rho \lambda}{k}\right) L_{3}{ }^{2} \Delta\left(\mathcal{N}_{\mathrm{v}} / \rho\right) .
$$

Figure I 3 is a graph of $E$ plotted as a function of the number of bonds in unit mass of the sample for five different snows. In general it verifies the linear relationship in Equation (8) and therefore indicates that $\rho \lambda / k$ is essentially constant as a given snow sample is nondestructively compacted.

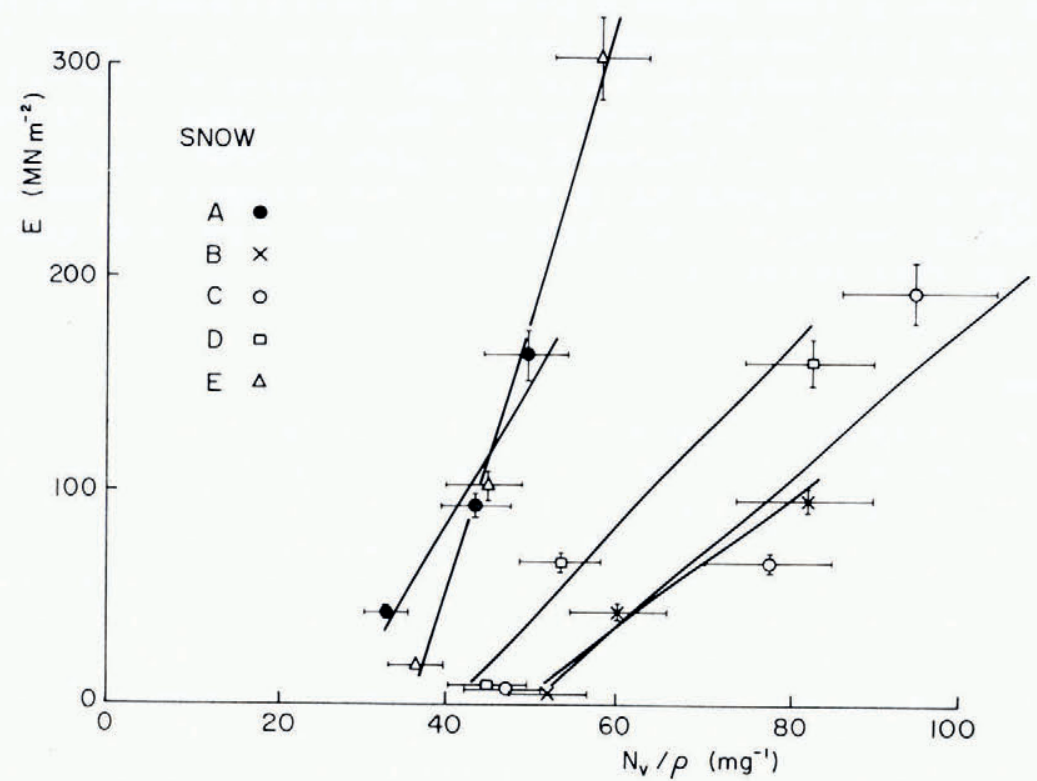

Fig. I3. Young's modulus $E$ measured at a strain-rate of $5 \times 10^{-4} s^{-1}$ as a function of the number of grain bonds per unit mass $\mathcal{N}_{\mathrm{v}} / \rho$ for each of five snow samples uniaxially densified.

The slopes of the lines in Figure I $_{3}$ are proportional to $(\rho \lambda / k) L_{3}{ }^{2}$. Therefore the variation in slope is in part due to a variation in the mean grain-size for the different snows. The factor $\rho \lambda / k$ also increases with mean grain-size. For snows which have different mean grain-sizes but whose chains have the same number of bonds (similar values of $k$ ), $\rho \lambda$ increases with the grain size. Table III verifies that larger values of the slope occur for larger grain-sizes.

TABle III. Mean intercept Length $L_{3}$ OF THE GRAINS IN EACH OF FIVE SNOW SAMPLES AND THE CORRESPONDING RATE OF CHANGE OF YOUNG'S MODUlus WITH RESPECT TO THE NUMBER OF GRAIN BONDS PER UNIT MASS

$\begin{array}{ccc}\text { Snow } & \begin{array}{c}L_{3} \\ \mathrm{~mm}\end{array} & \begin{array}{c}\text { Slope } \\ \mathrm{N} \mathrm{m}^{-2} \mathrm{~kg}\end{array} \\ \text { A } & 0.26 & 7.1 \\ \text { B } & 0.22 & 3.1 \\ \text { C } & 0.20 & 3.5 \\ \text { D } & 023 & 43 \\ \text { E } & 0.27 & 13.0\end{array}$




\section{Low-stress viscosity}

If the viscous deformation were purely due to bending near grain bonds then the variation of $E$ and $\eta$ with density would be exactly the same. However, for a $30 \%$ densification, $\eta$ varies by a factor of 30 (Equation (3)) whereas $E$ varies by a factor 15 (Fig. 8). This is the principle evidence that two mechanisms operate and that both can cause a stiffening of the structure as the density increases.

Thus the two viscous deformation mechanisms are viscous bending near grain bonds and viscous glide at crystal bonds (usually coincident with the grain bonds). Only the stiffening due to the bending mechanism parallels the elastic stiffening. It can account for a I5-fold increase in $\eta$ for a $30 \%$ densification. The viscous glide mechanism is not affected by decreases in the average torque in the chains because it is a shear deformation. As the chains become shorter, the influence on the deformation of the end grains increases compared with the effect of the link grains. The end grains have at least one more stressed bond than the link grains and thus they are less free to move. Therefore, the effectiveness of the glide mechanism decreases as the chains become shorter.

\section{Conclusions}

In a sample of alpine snow metamorphosed at one temperature, the visco-elastic properties are determined by the structure which distributes applied stresses over a fraction of the total number of grain bonds only. Since this fraction is directly affected by stress-induced deformation, the visco-elastic properties of a given snow sample are strongly related to its stress history.

In snow which has been densified in stages over a $30 \%$ range the mean grain-bond size remains constant while the total number of grain bonds increases linearly with density by a factor of from I.5 to 2. However, Young's modulus increases with density almost linearly an order of magnitude higher. The compressive viscosity under low stresses increases even faster, nearly exponentially with density for densities less than $380 \mathrm{~kg} \mathrm{~m}^{-3}$. Since the mean grain-bond size remains constant the gross difference in the rates of change of the grain-bond number density and the visco-elastic properties with density implies that a far smaller fraction of the grain bonds are significantly stressed in the original snow samples than in the densified snow samples. That is, applied stresses are transmitted by only a fraction of the total number of grain bonds.

Snow does not obey Hooke's law even when the stress is applied rapidly. However, after the initial non-linearity of the stress-strain relationship there is a range of strain $\left(>2 \times \mathrm{IO}^{-4}\right)$ for which a linear stress-strain relation is valid and for which a quasi-static Young's modulus can be defined. For strains less than $2 \times 10^{-4}$ the snow is stiffer in a structure-dependent manner. Moreover, the quasi-static Young's modulus is strain-rate dependent, but this is not a structural property. Both these effects cause dynamic measurement methods to yield larger values for the Young's modulus than those obtained using quasi-static methods.

Each type of deformation (elastic, viscous or plastic) possesses a different structural dependence. As the structure is densified in stages it becomes elastically stiffer almost linearly and more viscous almost exponentially, the normalizing plastic stress increases only very slightly provided that the density remains less than $380 \mathrm{~kg} \mathrm{~m}^{-3}$. Any model based on a structural mechanism must agree at least qualitatively with this behaviour.

The concept of a chain, a connected series of stress-bearing grains, as the fundamental unit of snow structure accounts semi-quantitatively for the observed variations in the viscoelastic properties of snow. The deformation of a chain is assumed to result primarily from a bending deformation in the neck regions of the grains close to the grain bonds. Viscous deformation is assumed to occur also by a viscous glide mechanism in the crystal bonds, which are generally coincident with grain bonds. 
With these principle assumptions the chain concept is able to provide an explanation of the deformation behaviour of snow. The initial non-linearity of the elastic response is due to the breaking of grain bonds which had been formed during a relaxation process immediately preceeding the test. The subsequent linear stress-strain behaviour is a result of a deformation of the chains which may be considered to be purely elastic. As the structure is densified, new grain bonds are formed, this decreases the average chain length and increases the number of chains. The increased normalizing plastic stress is due to the increased number of chains bearing the total stress. The increase in the quasi-static Young's modulus is due to a stiffening which occurs as the chains become shorter and less eccentric. The more rapid increase in the low-stress viscosity is attributed to a decrease in the contribution to the deformation rate made by viscous glide processes at crystal bonds as the chains become shorter. Shorter chains have fewer link grains and, therefore, the end grains play a more significant role because they have more stressed bonds and are less free to move.

These experiments have provided a basis for the chain concept and have established its validity and usefulness. To test and elaborate the concept further more experiments are required. These should involve controlled structural changes in snow and should also investigate the deformation of pairs and sequences of bonded ice-grains.

\section{Acknowledgements}

I am grateful for a Post-Doctoral Fellowship from the National Research Council of Canada. Thanks are due to the Institute Staff and Dr M. R. de Quervain for the scientific, technical, and financial support received. In particular I am indebted to Dr H. Gubler who helped to clarify, through our discussions, the concepts presented in this paper.

MS. received 9 September 1974 and in revised form 21 February 1975

\section{REFERENCES}

Bader, H., and Kuroiwa, D. 1962. The physics and mechanics of snow as a material. U.S. Cold Regions Research and Engineering Laboratory. Cold regions science and engineering. Hanover, N.H., Pt. II, Sect. B.

Ballard, G. E. H., and McGaw, R. W. 1965. A theory of snow failure. U.S. Cold Regions Research and Engineering Laboratory. Research Report i37.

Bradley, C. C., and St. Lawrence, W. In press. Kaiser effect in snow. [Presented at International Symposium on Snow Mechanics held in Grindelwald, Switzerland, I-5 April 1974.]

Feldt, E. D., and Ballard, G. E. H. 1966. A theory of the consolidation of snow. Fournal of Glaciology, Vol. 6, No. 43 , p. $145^{-57}$.

Gold, L. W., and Traetteberg, A. In press. Young's modulus of ice and ice engineering problems. [Presented at second Symposium on Applications of Solid Mechanics at the Dept. of Mechanical Engineering, McMaster University, Hamilton, Ontario, June, 1972.]

Hobbs, P. V. ${ }_{1965}$. The effect of time on the physical properties of deposited snow. Fournal of Geophysical Research, Vol. 70, No. I6, p. 3903-07.

Hosler, C. L., and others. 1957. On the aggregation of ice crystals to form snow, by C. L. Hosler, D. C. Jensen, and L. Goldshlak. Fournal of Meteorology, Vol. 14, No. 5, p. 41 $5^{-20}$.

Keeler, C. M. I969. The growth of bonds and the increase of mechanical strength in a dry seasonal snow-pack. Journal of Glaciology, Vol. 8, No. 54, p. 44 I-50.

Kennedy, A. J. 1962. Processes of creep and fatigue in metals. Edinburgh, Oliver and Boyd.

Krausz, A. S. ${ }^{1972}$. The activation volume associated with the plastic deformation of ice. Applied Scientific Research, Vol. 26, Nos. 1-2, p. 86-92.

Kry, P. R. 1975. Quantitative stereological analysis of grain bonds in snow. Fournal of Glaciology, Vol. 14, No. 72 , p. $467-77$.

Mellor, M. I964. Properties of snow. U.S. Cold Regions Research and Engineering Laboratory. Cold regions science and engineering. Hanover, N.H., Pt. III, Sect. AI.

Mellor, M. In press. A review of basic snow mechanics. [Presented at International Symposium on Snow Mechanics held in Grindelwald, Switzerland, I-5 April 1974.]

Mellor, M., and Smith, J. H. 1967. Creep of ice and snow. (In Öura, H., ed. Physics of snow and ice: international conference on low temperature science. ... 1966. . . . Proceedings, Vol. 1, Pt. 2. [Sapporo], Institute of Low Temperature Science, Hokkaido University, p. $843-55$. 
St. Lawrence, W., and Bradley, C. C. In press. The deformation of snow in terms of a structural mechanism. [Presented at International Symposium on Snow Mechanics held in Grindelwald, Switzerland, 1-5 April 1974.]

Salm, B. 1971. On the rheological behavior of snow under high stresses. Contributions from the Institute of Low Temperature Science, Ser. A, No. 23.

Wakahama, G. I 960 . Sekisetsu no hakuhen o ōyō shita sekisetsu no soshiki to naibuwai no kenkyū. I. Seikajū ni yoru sekisetsu hakuhen no asshuku [Internal strain and changes in the microscopic texture of snow caused by compression. I. Compression of a thin section of snow by a static load]. Teion-kagaku: Low Temperature Science, Ser. A, [No.] 19, p. 37-72.

Yosida, Z., and others. 1956. Physical studies on deposited snow. II. Mechanical properties (1), by Z. Yosida, H. Oura, D. Kuroiwa, T. Huzioka, K. Kojima, S. Aoki and S. Kinosita. Contributions from the Institute of Low Temperature Science, No. 9, p. I-8I. 